may deserve further study, 81516 provided investigators_even in the face of daily and severe attacks - can withstand the temptation to 'resuscitate' or give uncontrolled treatments.

Insufficient attention has been paid to the neurological basis of the active expiration which is an essential feature of breath holding attacks, but which may also be seen in those pallid syncopes (associated with cardiac asystole) induced by ocular compression in the laboratory. ${ }^{13}$ Obviously the oculorespiratory reflex is no more involved in natural breath holding than is the oculocardiac reflex in those 'reflex anoxic seizures' mediated by cardiac asystole, but it can be studied safely and ethically ${ }^{17}$ and it is not confined to man. What is self evident is that if continued brainstem neuronal drive is necessary to inhibit active inspiration and/or cardiac systole, then sufficient hypoxia and/or ischaemia must reverse this inhibition.

\section{Summary}

In their recent publication in this journal, Southall et al described typical cyanotic breath holding spells, both in otherwise healthy children and in those with brainstem lesions and other malformations. ${ }^{1}$ Their suggestions regarding possible autonomic disturbances may require further study, but they have adduced no scientific evidence to contradict the accepted view that in the intact child blue breath holding spells are benign.

Those families in which an infant suffers an 'apparently life threatening event' deserve immense understanding and help, and it behoves investigators to exercise extreme care and self criticism in the presentation of new knowledge which may bear upon their management and their morale.

1 Southall DP, Samuels MP, Talbert DG. Recurrent cyanotic episodes with severe arterial hypoxaemia and intrapulmonary shunting: a mechanism for sudden death. Arch $D$ is Child 1990;65:953-61.

2 Stephenson JBP. Fits and faints. London: Mac Keith Press/ Blackwell Scientific, 1990.

3 Meadow R. Suffocation, recurrent apnea, and sudden infant death. F Pediatr 1990;117:351-7.

4 Stephenson JBP. Reflex anoxic seizures ('white breathholding'): nonepileptic vagal attacks. Arch Dis Child 1978; 53:193-200.

5 Stephenson JBP. Prolonged expiratory apnoea in children.

6 Lombroso CT, Lerman P. Breathholding spells (cyanotic and pallid infantile syncope). Pediatrics 1967;39:563-81.

7 Laxdal T, Gomez MR, Reiher J. Cyanotic and pallid syncopal attacks in children (breath-holding spells). Dev Med Child Neurol 1969;11:755-63.

8 Hunt CE. Relationship between breath-holding spells and cardiorespiratory control: a new perspective. $\mathcal{f}$ Pediatr 1990;117:245-7.

9 Southall DP, Talbert DG, Johnson P, et al. Prolonged expiratory apnoea: a disorder resulting in episodes of severe artetory apnoea: a disorder resulting in episodes of severe arte-
rial hypoxamia in infants and young children. Lancet 1985; rial hypoxan $571-7$.

10 Southall DP, Lewis GM, Buchanan R, et al. Prolonged expiratory apnoea (cyanotic 'breath-holding') in association with a medullary tumour. Dev Med Child Neurol 1987;29: 789-93.

11 Gauk EW, Kidd L, Prichard JS. Mechanism of seizures associated with breath-holding spells. N Engl f Med 1963;268: $1436-41$.

12 Gauk EW, Kidd L, Prichard JS. Aglottic breath-holding spells. $N$ Engl $\mathcal{f}$ Med 1966;275:1361-2.

13 Maulsby R, Kellaway P. Transient hypoxic crises in children. In: Kellaway P, Petersen I, eds. Neurological and electroencephalographic correlative studies in infancy. New York: Grune and Stratton, 1964:349-60.

14 Gastaut H. A physiopathogenic study of reflex anoxic cerebral seizures in children (sycopes, sobbing spasms and breath-holding spells). In: Kellaway P, Petersen I, eds. Clinical electroencephalography of children. Stockholm: Almquist and Wiksell, 1968.

15 Kahn A, Rebuffat E, Sottiaux M, Muller MF, Bochner A, Grosswasser J. Brief airway obstructions during sleep in infants with breath-holding spells. $\mathcal{F}$ Pediatr 1990;117: 188-93.

16 DiMauro FJ, Chee CM, Berman PH. Pallid breath-holding spells. Evaluation of the autonomic nervous system. Clin Pediatr (Phila) 1990;29:17-24.

17 Blanc VF, Jacob J-L, Milot J, Cyrenne L. The oculorespiratory reflex revisited. Canadian Journal of Anaesthesia 1988; 35:468-71.

\title{
Cyanotic 'breath holding' and sudden death
}

\section{P Samuels, D G Talbert, D P Southall}

Dr Stephenson raises an important issue concerning the risk of sudden death during cyanotic breath holding. Our recent paper describes investigations to understand further the pathophysiological mechanisms responsible for severe cyanotic breath holding and did not attempt to estimate the risks of this disorder. ${ }^{1}$ To do this would require a population based study, ideally prospective in nature, in which there was almost complete follow up. The historical studies mentioned by Dr Stephenson are unable to confirm that no deaths occurred. Thus in the study of Laxdal $e t a l^{2}$ and Lombroso and Lerman, ${ }^{3} 18 \%$ and $43 \%$ respectively were lost to follow up. One possible reason for a lack of response to posted questionnaires might have been the death of a child.

We trusted that readers would not automatically infer from reading our paper that there is mortality of $16 \%$ in cyanotic breath holding. As stated, our patients were at the severe end of the spectrum and therefore not representative of the whole population of 'breath holders'. Furthermore, Hunt in his recent editorial did not claim that $15 \%$ of breath holders die, but was specifically referring to our collection of patients. ${ }^{4}$ Our cases were 'selected' by virtue of their referral to us by their paediatrician who, with the parents, was concerned about the severity of the hypoxaemic episodes.

Dr Stephenson omits to mention our own prospective population based study of sudden deaths between 1 and 5 years of age. ${ }^{5}$ This involved the follow up of 9856 infants all of whom were tagged for future death by the Office of Population Censuses and Surveys. Two of the deaths between 1 and 5 years in these 9856 children occurred during cyanotic breath holding. Based on Lombroso and Lerman's estimated incidence of cyanotic breath holding as $2 \cdot 8 \%$ of all children, ${ }^{3}$ around 276 of our 9856 cohort should have suffered from this 
disorder. Thus around two of 276 or $0.7 \%$ of children with cyanotic breath holding are likely to have a fatal outcome. If one can accept a $0.7 \%$ mortality rate, statements concerning the benign nature of this condition are correct.

There are three other reasons why we consider that the severe forms of cyanotic breath holding are not benign. Firstly unconsciousness is due to severe cerebral hypoxia and this is recognised as a cause of cerebral injury. Secondly our discussion with older children experiencing these episodes suggest that they are an unpleasant experience: children describe an inability to breath in and a feeling of suffocation. Finally, severe episodes frighten not only parents, but also experienced nursing and medical staff, who cannot accept that they are benign. The appearances of a child apnoeic, cyanosed, unconscious, developing rapid and profound bradycardia, does not appear compatible with a condition described as benign.

The rapid onset of severe hypoxaemia (falls in arterial oxygen tension to $2 \cdot 1-3.9 \mathrm{kPa}$ in 10 to 25 seconds) cannot be explained simply by low lung volume and rapid oxygen consumption. Although prolonged expiratory apnoea is the most frequent accompanying respiratory abnormality, we also reported that 'severe hypoxaemia may develop rapidly despite continued spontaneous or mechanical ventilation'. Hence we searched for a right to left shunt of desaturated, mixed venous blood. It was impossible for all patients to undergo all of the investigations necessary to confirm the development of an intrapulmonary shunt, but episodes in all 51 of our patients were in all other respects similar to those occurring during krypton infusion scans and contrast echocardiography. ${ }^{1}$

We do not advocate tracheostomy, which does not prevent episodes and by disabling laryngeal control may be detrimental. The tracheostomies in the patients who died were inserted before referral in order to ease resuscitation. We were also wary about commencing any medication and none of our eight cases who died was being treated with tetrabenazine or clonidine. However, when a child is having to be artificially ventilated using a bag and face mask several times each day (and we can reassure Dr Stephenson that this was required to avoid endotracheal intubation), then search for an effective treatment was considered ethical. We are now conducting a randomised, double blind, crossover trial of clonidine.

Dr Stephenson claims that insufficient attention was given to the 'neurological basis of the active expiration'. We did, however, discuss and reference studies where, for example, infusion of noradrenaline onto brainstem neurones produced apnoea. Recent work by Kaada reinforces our view that emotional responses may have profound effects on cardiovascular and respiratory reflexes. ${ }^{6}$ Dr Stephenson's figure is reported to show cerebral hypoxia with cardiac asystole. However, the recording does not illustrate oxygen or breathing signals; the reported cardiac asystole may be due to loss of electrode contact.

Dr Stephenson also implies that we should not have interfered with the natural history of episodes by attempting resuscitation. For the majority of young children with isolated and infrequent episodes we would agree with this opinion. However, for those with frequent episodes involving loss of consciousness, we consider Dr Stephenson's advice to be inappropriate; eight of 51 such cases reported in our paper died. Since our publication we have experienced an additional case which highlights the danger of adopting a conservative approach to the management of patients at the worst end of the spectrum of this disorder:

This infant presented at 6 weeks of age with severe hypoxaemic episodes which were clinically recognised as cyanotic breath holding. Investigations in our department confirmed the presence of active expiratory 'apnoea' and intrapulmonary shunting. His parents were given a transcutaneous $\mathrm{PO}_{2}$ monitor to identify any episodes that should occur when he was not being observed. His episodes had always occurred when he was awake and his mother did not believe that they would occur when he was sleeping. Nevertheless the episodes were considered by us and his referring paediatrician to be extremely dangerous and it was explained to his mother that an episode might occur if he awoke from sleep and became frightened or angry. One afternoon at the age of 10 months, he was settled to sleep in his cot (unattached to the oxygen monitor). Forty five minutes later his mother found him dead. A postmortem examination showed patchy congestion in the lungs with some milk in the larger airways; these findings were reported to be compatible with sudden infant death syndrome, although, because of his previous history, his death was certified as due to 'apnoea of infancy'.

In summary, the episodes of hypoxaemia described in our paper represented the severest form of cyanotic breath holding (a term which is unfortunate in that it implies a voluntary component). A functional disturbance, which involves intrapulmonary shunting and prolonged expiratory apnoea, represents the best explanation for the final pathophysiology leading to the sudden and unexpected deaths that occurred in eight of our 51 patients, despite the pathology found in some at postmortem examination. ${ }^{7}$ The risk of sudden death in all patients with clinically recognised cyanotic breath holding appears to be very low, but we would continue to be concerned by episodes in infants less than 6 months of age or in those with frequent loss of consciousness. The identification of an effective treatment will not only help in our understanding of the mechanisms responsible for these episodes, but may also improve the lives of many young infants and their families.

1 Southall DP, Samuels MP, Talbert DG. Recurrent cyanotic episodes with severe arterial hypoxaemia and intrapul episodes with severe arterial hypoxaemia and intrapulmonary shunting: a mech

2 Laxdal T, Gomez MR, Reiher J. Cyanotic and pallid syncopal attacks in children (breath-holding spells). Dev Med Child attacks in children (breath-

3 Lombroso CT, Lerman P. Breatholding spells (cyanotic and pallid infantile syncope). Pediatrics 1967;39:563-81.

4 Hunt CE. Relationship between breath-holding spells and cardiospiratory control: a new perspective. $\mathcal{F}$ Pediatr 1990 117:245-7.

5 Southall DP, Stebbens V, Shinebourne EA. Sudden and unexpected death between 1 and 5 years. Arch Dis Child 1987;62:700-5.

6 Kaada B. Sudden infant death syndrome. The possible role of 'the fear paralysis reflex'. Oslo: Norwegian University Press, 1986

7 Samuels MP, Southall DP. Recurrent cyanotic episodes with severe arterial hypoxaemia and intrapulmonary shunting: mechanism for sudden death. Arch Dis Child 1991 (letter in press). 